\title{
LA ENSEÑANZA DE LA FILOSOFÍA
}

Eduardo Calcin Figueroa*

No se puede aprender filosofía, tan sólo se puede aprender a filosofar. (Inmanuel Kant)

\section{RESUMEN}

Partiendo de una experiencia familiar este artículo reflexiona sobre la enseñanza de la filosofía y la tan discutida 'utilidad' de aprenderla, teniendo por referencia a Sócrates y Platón como los grandes metodólogos del aprendizaje y la enseñanza filosófica.

$\mathrm{El}$ autor parte del principio que el profesor debe ante todo amar la materia que imparte, acompañando y guiando al alumno durante el proceso de aprendizaje donde él construye su propio conocimiento, pues aunque asi bien no hay métodos para enseñar a pensar, esta actitud docente propicia el encuentro, el disfrute por el saber.

PALABRAS CLAVE: Filosofar, Didáctica de la filosofía, Metodología de la reflexión.

\section{TEACHING PHILOSOPHY}

\begin{abstract}
Taking into account a family experience, this article pretends to analyze Philosophy teaching and the so well discussed "importance" to learn it, having Socrates and Plato as great learning and philosophy teaching's methodologists. The author is based on the principle that professor should first love what he teaches, following and guiding the student during the learning process where it constructs its own knowledge, because even though there are no methods to teach and think, the teaching attitude leads the encounter, as well as the enjoy for learning.
\end{abstract}

KEYWORDS: philosophize, teaching philosophy, reflection methodology.

*Licenciado y Magíster en Teología por la Facultad de Teología Pontificia y Civil de Lima. Egresado de Maestría en Historia de la Filosofía de la Universidad Nacional Mayor de San Marcos. Actualmente cursa estudios doctorales Educación en la Universidad Marcelino Champagnat. Docente Ordinario en el Departamento de Filosofía y Teología en la UNIFÉ. Docente en la Universidad Marcelino Champagnat. 
Quisiera empezar el presente artículo haciendo referencia a una curiosa anécdota que me ocurrió en cierta ocasión: Habia quedado con mi bijo ir a jugarpelota en elparque, como cada sábado por la tarde; para ello, él se encontraba ya preparado con la ropa deportiva, esperándome. Por mi parte, trataba de terminar un trabajo de filosofía que estaba digitando en la computadora. Impaciente me preguntó: ¿Papá, qué haces?. Le contesté: Trato de terminar este trabajo....y y me falta poco. Él replicó: Papá, siempre te veo leyendo y trabajando... pero, si lees tanto y trabajas tanto, ¿por qué no tenemos más plata? Me agradó su observación y decidí aprovechar la ocasión para contarle la siguiente historia y transmitirle un mensaje. Le dije, ven siéntate a mi lado y déjame contarte una pequeña historia: Habia una vez. un hombre llamado Tales de Mileto que observando los astros y tratando de comprender como operaban, no se percató que frente a sus pies habia un hoyo, cayendo en él. Su criada quien le observaba se rió aduciendo que Tales queriendo conocer las cosas del cielo no advirtiera las cosas que estaban junto a sus pies. De aqui, que mucha gente criticara la pobreza e inutilidad del quehacer de Tales, quien era filósofo y cultivador de otros saberes, dado que, no otorgaba dinero o bonanza financiera. Pero, cierta ocasión; aun cuando era invierno y con el poco dinero que tenía arrendó todas las prensas de aceite que habian en las ciudades de Mileto y Quios. Las consiguió a un bajo precio pues no había competencia. La razón obedecía que gracias a sus estudios y conocimiento en astronomía sabía cuándo habría una buena cosecha de aceitunas. Y llegando la temporada de cosecha los agricultores fueron a buscar prensas de aceite y no las consiguieron. Tales las habia alquilado todas. Por lo cual, tuvieron que acudir a él. Y él se las alquiló por el doble y triple que habia pagado por ellas. De este modo, Tales obtuvo mucho dinero y demostró que fácil resulta a los filósofos y a los que estudian enriquecerse cuando quisieran hacerlo. (Aristóteles, Política I 11, 1259a). Terminado mi relato observé a mi hijo para ver cuál era su reacción. Y él me dijo: -Entendî papá....ahora vamos a jugar.

Tal vez, resulte sumamente curioso que si afirmamos que el filósofo podría enriquecerse si quisiera hacerlo, la pregunta inmediata que formularíamos sería: ¿Por qué no lo hace?. Muy simple, la actividad filosófica como cualquier quehacer humano es una ocupación que se sitúa o ha de situarse más allá del deseo de querer alcanzar el dinero o la fama. La motivación del filósofo es querer alcanzar un conocimiento amplio, claro y profundo de todas las cosas. Su sed insaciable de querer alcanzar la verdad lo define: "philosophon" ("amante del saber o de la sabiduría”). El filósofo es el que reconoce su ignorancia, pero quiere salir de ella; no tiene la posesión del saber, pero si aspira a él. El filósofo no puede mirarse como sabio, porque entonces no sería filósofo o amante del saber. El filósofo busca la sabiduría porque no la posee; ama el saber, pero si lo ama es porque se siente desposeído por él.

Platón aseveraba que al hombre sólo le corresponde el "amar la sabiduría" porque sólo a los dioses les correspondería el ser "sabio" ("sophon"), haber alcanzado la sabiduría. Justamente en ello consiste el "amor platónico". El término medio entre la sabiduría y la ignorancia; como el amor que no es bello ni feo, pero que el no ser bello ni feo no implica necesariamente ser feo y malo, como el no ser sabio no implica necesariamente ser ignorante. Así, quien no conozca algo o sepa algo, no significa que ignore todo. 
El desconocimiento que se presenta como defecto puede ser la condición base para la búsqueda del conocimiento. Como Sócrates quien reconociendo su propia ignorancia ("sólo sé que nada sé") indaga la verdad que se encuentra encerrada en cada hombre y la descubre por el ejercicio de la reflexión, el análisis, la interrogación. No es el hombre quien con su mente "crea" el conocimiento dentro de si; la mente humana "descubre" aquello que en la cosa hay de inteligibilidad, de cognoscible. Porque conocer es dirigir la inteligencia para "aprehender" la inteligibilidad de las cosas.

Conviene recordar que la mayéutica socrática consistía en adoptar una postura de no saber y dar por sentado que su interlocutor si sabía. Esta método filosófico empleado por Sócrates frente a los sofistas no era una postura o protagonismo de él, sino la actitud de alguien que quiere saber de aquellos que manifiestan saberlo todo, "solo sé que nada desconozco" era la frase de los sofistas. Mediante su método mayéutica que consistía en establecer un diálogo a partir de una pregunta que él formulaba y su interlocutor contestaba se iniciaba el debate en torno a un tema que exigía una respuesta clarificadora en torno a su definición; es decir, llegar a la verdad o el conocimiento del mismo. Le preocupaba que algunos hombres no viesen con claridad meridiana los principios $\mathrm{y}$ conclusiones que se desprendían de sus propias afirmaciones. A su vez, era un esfuerzo desesperado por despertar la mente de los atenienses y hacer volver la atención hacia los problemas más urgentes para la salvación de su ciudad.

En esto consistía su incansable actividad educadora, la siembra tenaz, insistente, machacona de despertar el pensamiento para que cada quien responda a sus propias preguntas o temas planteados por él, pero que requerían ser replanteados sobre todo por aquellos que consistían un grupo selecto de personas (sofistas) que ejercían medianamente su poder a través de aquellos que gobernaban o gobernarían las ciudades. Sócrates observaba también que los que están instruidos en los asuntos humanos pueden utilizar a voluntad en la vida sus conocimientos en provecho propio y ajeno. Por tanto, se preocupó en inquietar el proceso inductivo y deductivo del pensamiento de sus jóvenes alumnos. Él no discurría sino en asuntos humanos, estudiando qué es lo piadoso, qué lo sacrílego; qué es lo honesto, qué lo vergonzoso; qué es lo justo, qué lo injusto; qué es sensatez, qué es insensatez; qué la valentía, qué la cobardía; qué es la virtud, qué es la justicia....porque busca la norma ideal de la conducta humana.

Difícilmente podríamos decir que los instruía en cuestiones de orden moral y político. No encontramos en los diálogos de Platón momentos en que Sócrates esté concluyendo o zanjando una discusión, ésta siempre quedará abierta para un ulterior tratamiento. Porque plantear la posibilidad de un saber concreto, acabado, es traicionar la esencia misma del quehacer filosófico, como saber inacabado.

Sócrates no se jactaba de haber sido maestro de alguien. Todo lo contrario, él sabe que ignora muchas cosas. "Nunca fui maestro de nadie" nos dice. "Nunca transmiti saber alguno" afirma. De aquí que, el 
docente en filosofía no debe asumir un rol protagónico en el debate de la clase, negando o rebajando la intervención de los alumnos en el afán de querer responder al tema central que se discute. Porque, justamente es el alumno quien debe construir y recorrer su propio camino en el aprendizaje. Recordar siempre que Sócrates se mantuvo lejos del oportunismo y pragmatismo de los sofistas. Curiosamente el oráculo de Delfos develó que Sócrates era el hombre más sabio del mundo.

El profesor debe ser ante todo alguien quien ame la materia que imparte. Su labor consistirá en crear un ambiente idóneo para posibilitar el ejercicio del pensamiento y concluyentemente alcanzar la luz del conocimiento. Ha de acompañar y guiar al alumno durante el proceso de aprendizaje donde él construye su propio conocimiento. Si bien no hay métodos para enseñar a pensar, hay que propiciar el encuentro, el disfrute por el saber.

Conviene suscitar en nosotros - docentes en filosofía- algunas preguntas orientativas que vayan encauzando el sentido a la labor que realizamos. Estas posibles preguntas podrían ser ¿Por qué enseñar filosofía? ¿Para qué enseñar filosofía? ¿Qué debemos enseñar en filosofía? ¿Cómo enseñar filosofía? Sólo así nos sentiremos compenetrados en la labor que realizamos.

El profesor de filosofía como de cualquier asignatura, debe ser ante todo, alguien quien ama lo que hace y conoce los diferentes ámbitos de la materia que imparte. Un profesional competente que se encuentra preparado en un nivel superior que el alumno quisiera llegar alcanzar. Porque si ha llegado al lugar de profesor, es seguro que es alguien quien ha estudiado, y esto solo se consigue disfrutando con el estudio. Sólo así y desde esa posición es capaz de suscitar el interés y agrado de cada uno de los temas discutidos, analizados, contrastados...durante la clase.

Un filósofo ha de ser a su vez un pedagogo porque su labor es posibilitar el descubrimiento, la apropiación cognoscitiva y la aplicación adecuada de los saberes. Saber ordenar el tiempo y los espacios es imprescindible y necesario para que se realice el proceso del aprendizaje. Han habido eruditos, maestros, profesores conocedores de su materia, pero que han sido también demasiado incompetentes para poder transmitir lo que conocían. El docente en filosofía debe reconocer que conocer la metodología didáctica apropiada es fundamental en una enseñanza moderna donde el sistema escolástico aparece como caduco y desfasado. La tecnología ofrece hoy muchas posibilidades para que el docente pueda recrear de manera didáctica, amena, interesante una clase. Pero ello, no ha de significar el abandono de la cátedra porque no se podría hacer auténtica filosofía si no se discurre bajo la guía o tutela de alguien quien ya conoce el camino.

Para la enseñanza de la filosofía en un centro de estudios superiores se requiere de un Programa o Syllabus que presente el contenido temático del curso que se dictará durante el año o semestre académico. La existencia de un Programa no traiciona la libertad de cátedra en el ejercicio de la labor docente para el curso de filosofía. Los programas son elaborados por un equipo de docentes 
especialistas en la materia, quienes mediante un proceso deliberativo han seleccionado determinados temas que responden a las nuevas circunstancias sociales y que podrían cambiar en el tiempo según la necesidad.

El Programa o syllabus debe ser desarrollado progresivamente en cada sesión de aprendizaje que debe tener una estructura coherente donde el profesor presenta a los alumnos un problema tomado de la cotidianidad, suscita la participación mediante el aporte espontáneo de las diversas ideas o respuestas, convirtiéndolos en contenidos a tratar y que responden a determinados logros que se desea alcanzar, basándose en métodos y estilos propios, en función de desarrollar competencias múltiples. Sucintamente podríamos referir que una sesión de aprendizaje debe tener las siguientes etapas: Inicio - Desarrollo Término.

a) Inicio: La motivación resulta imprescindible en todo acto de enseñanza para el aprendizaje. La mayor parte de los problemas que se presentan en el aprendizaje por parte de los alumnos en los centros de enseñanza superior es el resultado de la falta e inadecuada motivación por parte del docente. Así, el alumno desmotivado, sea por la perso-nalidad del docente, su compor-tamiento autoritario, por la falta de material didáctico adecuado, por un inadecuado método de enseñanza, etc; lo llevan a un desinterés y rechazo de un tema que de suyo pudiera ser interesante.

La motivación es uno de los factores que aunado a la inteli-gencia y los saberes previos, determinarán si los estudiantes lograrán alcanzar las compe- tencias o capacidades propuestas. La motivación tiene por finalidad suscitar el interés e involucrar al alumno en el tema a desarrollar. El alumno participando activa-mente mediante el aporte de ideas, estará evidenciando el aprendizaje es significativo y que existe una adecuada motivación.

En la enseñanza de la filosofía podría servir como elemento motivador una noticia de actualidad, un video breve (no más de 10'), una pregunta formulada en forma general, el fragmento de una obra literaria o filosófica, etc. A su vez, conviene explicar qué es lo queremos que nuestros alumnos presten aten-ción; evitando así, la atención en elementos secundarios que no nos interesa resaltar. Seguida-mente, se procederá a recoger los aportes mediante una lluvia de ideas, resaltando las interven-ciones que nos servirán para ir centrando el tema a tratar. De este modo, pasaremos al desarrollo del tema de nuestra clase.

b) Desarrollo: El profesor es un factor esencial en el proceso de la enseñanza de la filosofía. Mediante un uso del lenguaje apropiado el docente podrá cumplir su misión de hacer que sus alumnos accedan al nivel de la reflexión crítica, que no se compagina con la ambigüedad, la vaguedad o la rigidez.

Enseñar no superficialmente, sino poner al alcance del alumno el producto elaborado de los conocimientos, experiencias y reflexiones que se han adquirido a lo largo de varios años y en el proceso de aprendizaje. Recurrir como fuentes de primera mano a obras escritas por los mismos filósofos, extrayendo de ellas las ideas fundamentales e invitando a la lectura de los mismos. 
La propia experiencia de la vida ayuda a nutrir las clases de filosofía, porque la vida misma no está al margen de esta disciplina, sino que es en ella en si misma una fuente inagotable de donde brotan las más diversas y variadas preguntas filosóficas.

En el desarrollo de la exposición, el docente podrá utilizar recursos auxiliares como: pizarra, trans-parencias, proyector multimedia, etc. En esta parte, no se aconseja que los profesores permitan que los alumnos desarrollen todo los temas del syllabus mediante ciclos de exposiciones. Las razones obedecen a lo siguiente: 1) Los alumnos no son de la especialidad, 2) Los términos y argumentos no siempre son accesibles a la comprensión de los iniciados en filosofía 3)El desarrollo del pensamiento presupone el dominio del contexto político, social, cultural..etc. En su defecto, puede asignarse temas específicos de investigación para que el alumno beba el conocimiento de la misma fuente del saber.

c) Término: La labor docente no termina con la exposición del tema o de la clase, de ser así; nos encontraríamos frente a un sistema antiguo donde el profesor aparece como el dador de conocimientos y lo único que le corresponde al alumno es escuchar y acatar pasivamente el oráculo de su maestro.

Seguramente el alumno aprenderá memorísticamente el concepto o sistema de pensamiento del filósofo expuesto: Pero, ¿podrá aplicar este nuevo conocimiento a nueva realidades? ¿Sabrá contrastarlo? ¿Podrá argu-mentar favorable o desfavo-rablemente?..etc. Evidentemente que no. Para que ello pueda ser posible se tiene que dar el proceso de transferencia. Este proceso significa que cuando lo que se aprende en una situación facilita el aprendizaje o desempeño o en otras situaciones. Si se descarta esa transferencia del conocimiento no se justificaría la enseñanza y con ello, la existencia de las instituciones educativas.

Los centros de estudios superiores preparan a los jóvenes para insertarlo en el mundo laborar y puedan resolver situaciones nuevas muy propias de una sociedad que avanza vertiginosamente en la senda del progreso y perfeccionamiento de la ciencia y técnica. El proceso de trans-ferencia en clase puede efectuarse a través de análisis de textos, películas y/o elaboración de ensayos. 


\section{Referencias}

- Bunge, Mario. (2007). Una filosofía para el nuevo milenio. Lima: Universidad Inca Garcilazo de la Vega.

- García, Juan José y Rodríguez, Ramón. (2007). Cómo se comenta un texto filosófico. Madrid: Ed. Síntesis.
- Lipman, M; Sharp, A.M y Oscanyan, F. S. (2002). La filosofía en el aula. 3ra ed., Madrid: Editorial De La Torre.

Salazar Bondy, Augusto (1967). Didáctica de la filosofía. Lima: Ed. Arica. 